\title{
Individuals, Groups and Intergroups: Theorizing About the Role of Identity in Conflict and its Creative Engagement
}

\author{
Jay Rothman* and Michal Alberstein**
}

\section{INTRODUCTION}

Over the past decade and a half, it has become increasingly common to proactively engage identity issues in conflict situations. This trend may be considered to be part of a second generation in the growing field of conflict studies and intervention.

In this paper we attach central importance to identity. In our view identity is not merely one of the many basic human needs, rather, it is a distinct category that underlies all conflicts. We examine expressions of identity with reference to three distinct levels of analysis: individual identity, group identity, and intergroup identity. ${ }^{1}$ We further contend that second generation conflict engagement models, which include Transformative

${ }^{*}$ Associate Professor, The Conflict Management, Resolution and Negotiation Program, Bar Ilan University.

** Associate Professor, Faculty of Law, Bar Ilan University. Head of Conflict Management, Resolution and Negotiation Program, Bar-Ilan University.

${ }^{1}$ Numerous trilogies have been used to identify identity. We use this specific formula in part due to Rothman's prior use of the typology in his work in conflict resolution assessment over the past two decades. See THEORY AND PRACTICE IN ETHNIC CONFliCt Resolution: THEORIZING SuCCESS AND FAILURE 1-23 (Marc Ross \& Jay Rothman eds.,1999); FROM IDENTITY-BASED CONFLICT TO IDENTITY BASED COOPERATION: ARIA APPROACH IN PRACTICE (Jay Rothman ed., 2012) (In this book the three levels of personal, group and intergroup conflict and cooperation are explored). Political Scientists John Burton and Edward Azar, with whom Rothman did his graduate work, advocated that the group level, too long overlooked in international relations theory, was most adductive of the fault lines in international relations that lead to protracted social conflicts and therefore most useful for addressing international conflict. Edward E. Azar, The Management of Protracted Social Conflict: Theory and CASES (In this book the authors explore the interconnections between ethnic and communal conflict within nations and its protractedness based on underdevelopment and threatened human needs) (1990); JOHN WEAR BURTON, CONFLICT: HUMAN NEEDS THEORY (1990); EDWARD E. AZAR \& JOHN WEAR BURTON, INTERNATIONAL CONFLICT RESOLUTION: THEORY AND PRACTICE (1986). For an understanding of Charles Sanders Peirce's use of the term abductive as a synthesis of inductive and deductive reasoning, see Nathan Houser \& Christian Kloesel, The Essentlal Peirce: Selected PHILOSOPHICAL WRITINGS (1992). 
Mediation, ${ }^{2}$ ARIA, ${ }^{3}$ and Narrative forms, ${ }^{4}$ can be characterized at least in part by their shift in attention from individualistic identity to group identity. ${ }^{5}$

Moreover, some of these newer approaches to theory and practice also aspire to delineate an intermediate level between the group and the intergroup. We view this stage as intermediary, or transitional, because while it does not revert back to the individual level, neither does it rise up to the overarching construction of intergroup identity. In this stage, which is both complex and deconstructed, the boundaries of the group identity become problematic for the individual members and the emotions that underlie his or her attachment to the group may be exposed. In order for intervention to proceed and succeed it is crucial that group identity be maintained, ${ }^{6}$ but the cognitive threads that hold this identity together may become shaky. Thus, within this intermediate level, it is possible to interactively reach new ways to (re)construct loyalty to the identity group and to simultaneously cooperatively engage the concrete conflicts that stand between groups,

2 The two main goals of transformative mediation are to empower the disputing parties and to enhance each party's recognition of the other. See Joseph P. Folger \& Robert A. Baruch Bush, Transformative Mediation and Third-Party Intervention: Ten Hallmarks of a Transformative Approach to Practice, 13 MEDIATION Q. 263, 278 (1995).

${ }^{3}$ ARIA is a framework for transforming identity conflicts developed by Rothman and named after the four phases of its process: Antagonism, Resonance, Invention, and Action. See JAY ROTHMAN, RESOlving IDENTITY-BASED CONFLICT: IN NATIONS, ORGANIZATIONS, AND COMMUNITIES 17-20 (1997) ("Antagonism surfaces the battle...Resonance fosters a harmoney that can emerge between disputants....Inventing is a process of brainstorming mutually acceptable, creative and integrative options for addressing central and underlying aspects of the conflict...Action is then built upon the previous stages, implementing what should be done and why, by whom, and how?').

${ }^{4}$ According to narrative perspectives, stories or narratives create social reality. The task of the mediator, then, is to destabilize and open up conflict narratives in order to permit the development of a joint story. See Sara Cobb, Empowerment and Mediation: A Narrative Perspective, 9 NEGOTLATION J.245, 245-55 (1993).

${ }^{5} \mathrm{We}$ also note that these ideas share theoretical roots with Social Identity Theory, which suggests that an individual's self-concepts and identities are significantly formulated and maintained by the social/cultural contexts of which he or she is a part. See, e.g., SOCIAL IDENTITY AND INTERGROUP RELATIONS 2 (Henry Tajfel ed.,1980) ("social identity will be understood as that part of the individual's self concept which derives from their knowledge of their membership of a social group (or groups) together wit hthe value and emotional significance attached to that membership"), DOMINIC ABrams, SOCIAL IDENTITY ThEORY: CONSTRUCTIVE AND CRITICAL ADVANCES (1990).

${ }^{6}$ We theorize that group identity must be maintained because it is ultimately necessary in order to sustain the emergent and inclusive new identifications-but that is a discussion for a different paper. 
without breaking up the group identity and resorting back to the individual level.

\section{THEORIZING ABOUT IDENTITY IN CONFLICT}

This paper is the first joint effort by these authors to both examine the expression of identity in the three levels of analysis and to locate identity within the genealogy of the field of conflict resolution.

As we define it, identity is a self-perception filled by a cultural formula. According to this definition, identity can most usefully be described by and conceptually organized into three main categories: Individual Identity (I am because I am), Group (I am because We are) and Intergroup (I am because We Are Linked with Each Other as both Individuals and Groups).

When referring to these three levels of identity our basic assumption is that, while some aspects of identity are ascribed, identity more generally emerges as a social construct. ${ }^{7}$

Let us expand further on these three levels before discussing their relevance to conflict.

\section{A. Individual Identity}

At the individual level the cultural formula we suggest is the notion, which dates back to the Enlightenment, that people are both individualistic maximizers of personal needs and goals and social beings who pursue the fulfillment of their individual needs and goals through interaction with others. At this level we use identity to explain how individuals, in the context of the groups of which they are a part and which form their culture(s) - such as familial, communal, national, religious, ideological, gender, professional, etc.-articulate what is most meaningful to them as they understand, pursue, and organize their lives, relationships, choices, loyalties, etc.

\section{B. Group Identity}

We subdivide this category in to two. The first is the collectivist level (which has also been somewhat pejoratively called the primordial or even primitive) in which individuals do not significantly distinguish themselves from the ethnic or group of which they are a part and which they collectively constitute. In this category self-interests are collective, communication is

7 Once again, we note the relationship to these theories and theories of social identity. See TAJFEL, supra note 5. 
sometimes high context (that is, places more emphasis on context and less on verbal exchanges), and power distance is high (that is, society is hierarchical rather than equal). ${ }^{8}$ The second level, which we label relational, is more modernist and the individual prioritizes at least significant aspects of his life and choices with reference to relationships, membership in and loyalty to a specific group (or range of groups). This conforms to a pluralistic notion of collective identity, according to which groups-and not the individuals that constitute them-form the building blocks of society. As units of analysis, groups intersect with other groups in order to maximize individual needs and interests. In this modernist version, group identity suggests a political challenge to an existing hegemony. Furthermore, it reflects philosophical developments in Western thought in a reactive response to individualism and challenges the ideology of separation and maximization as inherent human qualities. ${ }^{9}$

\section{Intergroup Identity}

This cultural formula of social relations suggests an ideal in which individuals constitute groups, choose their loyalties and flow between them flexibly, and can forge alliances for the good of all. This conceptualization reflects an ideal process of amalgamation, in which the most pro-social elements of different groups are pieced together on a complex and contingent basis in order to take advantage of the opportunities that real life presents and to meet its challenges.

This process of amalgamation entails continuous identity negotiation. On the one hand, this negotiation maintains some verticality and stability because it is deeply rooted in history, culture, values, origin myths and so forth. On the other hand, this process can also adapt itself horizontally to the changing demands of complex and multidimensional polities and real-time group loyalties. ${ }^{10}$

Within this framework, people oscillate among diverse subject positions; following each move, they are subject to concrete group identity. This agency does not primarily stem from efforts to maximize self interest (which occurs at the individual level) or from holding on to a specific group as a

8 See Edward HALl, BEYOND CULTURE (1976).

${ }^{9}$ See generally MICHAEL SANDELL, LIBERALISM AND THE LiMITS OF JUSTICE (1982); Carol Gilligan, In A Different Voice: Psychological Theory and WOMEn's DEVELOPMENT (1982).

10 Clifford Geertz, Avallable Light: ANThropological Reflections on PhILOSOPHICAL TOPICS 110 (2000). See generally Charles TAYLOR, THE ETHICS OF AUTHENTICITY (1991). 
defense against mainstream individualism (which occurs at the group level). Rather, it derives from an individual's self reflection regarding the fragility of cultural boundaries and his recognition that transitivity, accompanied by a mild capacity to proactively rewrite certain scripts of his or her own cultural amalgamation, represents freedom of choice. Ideally, when constructive conflict intervention is introduced, this may in turn develop into a position that is more inclusive of the "other." Indeed, according to our understanding, conflict and identity can be co-constructive, as they limit and help to demarcate what is important and meaningful to each party, individually and collectively. ${ }^{11}$

This understanding is also rooted in narrative analyses of identity that suggests that through language and interaction we create and recreate each other and ourselves by telling stories about who we are and what matters to us. ${ }^{12}$ Indeed, modern (albeit primarily Western bourgeoisie) identity is now perceived as a profoundly unfolding, never static story that is reconstructed again and again in each discursive exchange. Furthermore, this process has accelerated exponentially over the past few decades; the advent of email and Google serve as key symbolic and practical markers of the extent to which our world has become increasingly smaller and interactive. And while this dynamism is disconcerting for those who would hold fast to old ways and who seek cultural stability as a bulwark against change, it also provides a valuable background for conflict engagement work. Thanks to this dynamism, conflict engagement is now able to creatively braid between the different experiences of identity that the parties create for themselves. ${ }^{13}$

In asserting that identity should be regarded as a category in its own right when analyzing and intervening in conflict, we challenge a common notion among scholars that identity is but one of a number of human needs whose frustration leads to conflict. ${ }^{14}$ Instead, we view identity as a distinct set of

11 We note here the work done by Jeffrey R. Seul around identity and conflict. Interestingly, Jeffery R. Seul suggests adapting development levels in a manner parallel to the identity levels we discuss in this paper. See Jeffery R. Seul, How Transformative Is Transformative Mediation?: A Constructive-Developmental Assessment, 15 OHIO ST. J. ON DISP. RESOL. 135 (1999-2000).

12 JEROME BRUNNER, Life as Narrative, 54 SOC. RES. 691 (1987).

13 Sarah Cobb, Narrative "Braiding": Negotiating Identity and Transforming Conflicts (unpublished document, on file with author).

14 The needs approach to identity-based conflicts suggests that the main cause of such conflicts and the reason they are often unresponsive to conventional negotiation and even to interest-based bargaining is that they are rooted in the threat and frustration of basic human needs and their fulfillment. Such needs are variously defined by different negotiation, peace, and conflict theorists. John Burton (1979) described them as irreducible collective human needs for security, predictability, recognition (of distinctive 
core concerns determined by group loyalties, social ideologies, and identification with specific social narratives about history and particular expressions of culture. Furthermore, although identity is historically rooted, we view it as an evolving and socially constructed ideological framework rather than as a fixed ontological reality that is frozen in time and place.

This has significant positive implications for the study and practice of identity-based conflict and conflict engagement. However, we are quick to add that unlike many of our colleagues (see discussion below about work around difficult conversations) we do not consider separate identities and group identifications to be so malleable that they can be viewed as a mere hindrance to improved social relations. Nor do we view identifications as obstacles that must, can, and eventually will be overcome. Encounters between identities should not be considered "a clash of civilizations," 15 master-slave destructive dynamics, ${ }^{16}$ or difficult legal issues that should be determined through interpretive acts by a Supreme Court. ${ }^{17}$ Rather, if, as we suggest, identities form as an underlying layer in any conflict, then proactively and constructively engaging them, while working with the right mode of conflict resolution, is key to any constructive conflict intervention. ${ }^{18}$

\section{LEVELS OF IDENTITY: INDIVIDUAL, GROUP, AND INTERGROUP}

Analysis of the levels of identity impact the mode of conflict resolution that is chosen. Pragmatic problem solving models focus on the individualistic level of conflict and the individual interests of disputants. Legal ADR modes of intervention and theorizing, including many negotiation models and

identity), distributive justice, meaning, and control. See BURTON, supra note 1. Negotiation theorists Dean Pruitt and Jeffrey Rubin (1986) defined them as needs for security, identity, social approval, happiness, and clarity about one's world, and physical well-being. See Dean G. PruitT \& Jefrrey Z. Rubin, Social Conflict: Escalation, Stalemate AND SETtLEMENT (1986). Peace studies pioneer Johan Galtung articulated needs for security, freedom, welfare and identity. See JOHAN GALTUNG, TRANSCEND AND TRANSFORM: AN INTRODUCTION TO CONFLICT WORK (2004).

15 See generally SAMUEL P. HunTINGTON, THE Clash OF Civilizations AND THE REMAKING OF WORLD ORDER (1996).

16 See generally GeORge W.F. Hegel, Phenomenology of SpIRIt (Amold V. Miller trans., 1977).

17 RoBert M. Cover, Nomos and Narrative, in NARRATIVE, VIOLENCE, AND THE LAW 101, 101 (1995).

18 Indeed, one work suggests that peace may be in part nurtured through engaging the differences that are inherent in identity. See generally NIKKI R. SLOCUM-BRADLEY, Promoting CONFLICT OR PEACE Through IDENTITY (2008). 
principled bargaining, ${ }^{19}$ are prime examples. ${ }^{20}$ More social-psychological and psycho-dynamically derived modes, such as interactive problem solving, also focus on an individualistic perception of identity and view individual needs as basic building blocks of groups that turn into the primary source of deeply rooted conflicts when those needs are threatened or frustrated.21

In contrast to these interest-based and needs-based schools, which formed the first wave in the field, some second generation models, such as the ARIA model and the Kumi approach, deal more directly with collective identity issues. ${ }^{22}$

In the third level of identity that we discuss in this paper, individuals and groups transcend their own separateness and link with others in other previously constituted groups to form a larger whole. We refer to this as the intergroup, and it both builds upon and deconstructs separate group identities. $^{23}$

Assuming that identity is crucial for the understanding of conflicts, how do people express their identity in conflict situations? If people differ systematically according to the manner in which they perceive their identity in a conflict, how does this systematic difference impact upon the ways in which the conflict should be engaged? What is the right method to diagnose their identity level? Which model of conflict intervention corresponds to which level of expression?

In this section we will begin to answer these questions by outlining more extensively the three existing notions of identity within Western thought:

${ }^{19}$ See generally Roger Fisher \& William L. Ury, GetTing To Yes: NEgotiating AGREEMENT WITHOUT GIVING IN (1991).

${ }^{20}$ For a critique of the managerial formal individualistic framing of ADR in general, see Sally Engel Merry, Disputing Without Culture: Review Essay of Dispute Resolution, 100 Harv. L. Rev. 2057, 2057-60 (1987); Kevin Avruch, Culture and Conflict RESOLUTION (1998).

21 Azar, supra note 1; Burton, supra note 1; Herbert C. Kelman, SocialPSYCHOLOGICAL DiMENSIONS OF INTERNATIONAL CONFLICT, in PEACEMAKING IN INTERNATIONAL CONFLICT: METHODS AND TECHNIQUES, 191-237, (2001).

22 Rothman, supra note 1 . The Kumi model has been constructed out of a series of models in an attempt to merge cutting-edge approaches to identity-based conflicts with best practices in sustained, community development. See JAY ROTHMAN, Ibid, Chapter 5, $\mathrm{http}: / /$ www.transform-centre.org/coneng/conflict-engagement/ (last visited Dec. 13, 2012).

${ }^{23}$ The narrative model of Winslade and Monk may also fit well here, since the authors explicitly depict the multiple identity as the foundation of their model, and discuss the constructive potential of moving among subject positions. See JOHN WinSLADE \& GERALD MonK, NARRATIVE Mediation: A NeW APPROACH TO CONFLict RESOLUTION 45 (2000). 
Individual level, Group level, and Intergroup level. ${ }^{24} \mathrm{We}$ illustrate a methodology we are currently developing for diagnosing identity by presenting specific written expression of identity within a conflict intervention. Finally, we classify existing models of conflict engagement according to the typology we offer.

\section{THE INDIVIDUAL LEVEL OF IDENTITY}

In 1789, the French Revolution provided the first challenge to traditional, tribal, regional and religious identities. The new nationalism offered individuals (or coerced them into) thinking of themselves as individuals and as entitled members of a nation-state, on the condition that they reduced their loyalty and primary affiliation to their separate groups. In theory, at least, an individual could be accepted as a fully-entitled Frenchman as long as he viewed his other identifiers as less salient (be they religious, ethnic or cultural). ${ }^{25}$

In this classic liberal perception, the individual expresses his identity by articulating his inner needs, monitoring his desires and emotions and interacting in a rational manner with other individuals who are similar in nature. The individualistic notion of identity defines it in terms of the needs, rights, or interests of the parties as natural and given and asserts that there is a good way to reconcile them and explore some opportunities for synergy.

The individualistic subject aspires to maximize his wellbeing and to preserve his human dignity and yet, in both the utilitarian and the ontological senses, he is bound by a set of moral and legal rules that limit these activities. An individualistic perception of identity corresponds to a discourse of legal rights in which safe interactions are instructed by law and agreements are reached by mutual understanding based on freedom of the will. Discussions of feelings and relationships are conducted in personal terms, referring to notions such as fairness and equality. ${ }^{26}$

24 We note that there is another level of identity that is related to a pre-modern notion of development. This is relevant to indigenous communities and traditional intervention methods of conflict resolution, in which there is little differentiation between the individual and his group. In this paper we discuss only Western notions of identity as they are relevant to modern Conflict Resolution studies, although we do discuss, below, the position of such communities situated within the larger Western context.

25 Interestingly, the notion that particular collectivities must be subsumed by national unity and obedience corresponds to the individualistic ideology-as-identity that was refined through the American Revolution in which Life, Liberty and the Pursuit of Happiness became the new world's secular religion.

26 JoHn RAWLS, A THEORY Of JUSTICE 54-117 (1971). 


\section{INDIVIDUALS, GROUPS AND INTERGROUPS}

Most of the first generation of thinking about mediation is based on the liberal notion of identity as an individual choice that resists conformity and group identification. ${ }^{27}$ This assumes that individuals can talk to each other, explore their separate and overlapping interests, invent options for mutual gain, or merely empower themselves and recognize each other. ${ }^{28}$ Although the distinctions between needs, rights and interests are regularly blurred, it is assumed that a good way exists to reconcile them and to explore opportunities for synergy.

Expressions of individual-level identity may appear in every conflict, even if the conflict entails encounters between groups and involves communal concerns. Indeed, when individuals involved in a conflict describe their needs and aspirations, they sometimes refer to their own personal attributes.

As an example: In the course of a mediation effort of a conflict between police officers and the black population in Cincinnati, a participant explains why he wants to maintain positive interaction between the police and the community:

I'm a God fearing man trying to get closer to God. I was raised in a family where we functioned together and had good communication. I learned that communication is very important - me and God, me and you, me and a police officer. We need to communicate with each other. Then maybe we wouldn't have so many scared officers on the street. ${ }^{29}$

27 See generqlly, e.g., ROBERT A. BARUCH BUSH \& JOSEPH P. FOLGER, THE PROMISE OF MEDIATION: RESPONDING TO CONFLICT THROUGH EMPOWERMENT AND RECOGNITION (1994).

${ }^{28}$ According to the Transformative Model by Bush and Folger, this is more of a "We" story than an " $I$ " story. However, we must qualify this assertion, since the model is constituted of and ultimately further reifies the Self-even if that Self is defined in relationship. The Self is empowered and the ability of individuals to make choices and to respond to other is improved. No reference to the social unit or the cultural background is made. See BUSH \& FoLGER, supra note 27.

29 This quote and those that follow are derived from a collaborative process designed and conducted by Rothman following unrest between police and community in Cincinnati, Ohio in 2001. See Jay Rothman \& Randi Land, The Cincinnati PoliceCommunity Relations Collaborative, 18 CRIM. JUSTICE 35-42 (2004). See generally Jay Rothman, Applying Action Evaluation on a Large Scale: Cincinnati Police-Community Relations Collaborative - Successes, Failures and Lessons Learned in FROM IDENTITYBASED CONFLICT TO IDENTITY-BASED COOPERATION: THE ARIA APPROACH IN THEORY AND PRACTICE 191 (Jay Rothman ed., 2012); Jay Rothman, Identity and Conflict: Collaboratively Addressing Police-Community Conflict in Cincinnati, Ohio, 22 OHIO ST. J. ON DISP. RESOL. 105 (2006). The quotes here are all taken from the data gathered 
In the context of the conflict between police and the African-American community, this man describes his aspirations for a better future through references to his personal beliefs and background. He speaks in his own name and in the name of his family. His notions are individualistic and yet, in his view, they apply universally to all human beings, since, in the individualistic perception, all individuals are considered alike.

Similarly, an African American youth explains that individual accountability is key:

I believe that everyone is an individual human being and that there is good and bad in all of us. I also believe that everyone has to be accountable for their actions: for example each member of my community has to also be held accountable on an individual level and not lumped into a group. ${ }^{30}$

From the "other side," a police officer also appeals to the links between individuals in order to build a new bridge for a better future:

I believe and teach my children to believe that respect for everyone in the community is essential to be a good person and that obeying the law and respecting the police is the easiest and first step to that. A society where people love, care, respect, and take care of each other can only truly occur when everyone agrees to cooperate and follow set guidelines that they as citizens helped establish. People must take responsibility for themselves and their children and teach them how to be good people themselves. ${ }^{31}$

These examples emphasize self-perception that is based on an internal, coherent center of the self, driven from within and yet naturally reaching out to others in inclusive ways. This self-perception assumes individuality, but even in its uniqueness, the self is seen as incorporating the larger context and existing in relationship with the other.

\section{A. Group Identity}

By the turn of the 19th century, nationalism and coerced conformity to an overall nationalistic identity through assimilation had become the Western ideal. The American "melting pot," for example, was viewed as the best route to "one nation." However a counter-movement emerged in the late

during the intervention described above and are on file with the author, hereafter: The Data.

${ }^{30}$ See The Data, supra note 29.

31 See The Data, supra note 29. 
1920 's, proclaiming that America's strength lay in its constitution as a "nation of nations." This alternative movement dignified the reality of cultural pluralism, in which each group had its own place. Horace Kallen, its founding theorist, analogized it to an orchestra in which a musical section, (such as the violinists), make harmony through the interrelations with other groups (such as the cellists). ${ }^{32}$ The next phase in the conceptualization of identity in Western thought thus belongs to the critique of liberalism, characterized by a move towards a more general collective notion of identity. It is through thinkers such as Marx, and Weber ${ }^{33}$ as well as Gadamer ${ }^{34}$ that we begin to see how the identity of the individual is projected and filled by social scripts and narratives. When outside forces, such as culture and community, have the most powerful shaping influence on an individual's identity, then its social quality provides the most relevant perspective.

Thus, identity at this phase is perceived as collective, cultural or social, and working with identity requires ethnographic sensitivity and acknowledgement of incommensurability and difference. According to this perspective of identity as socially constructed and shaped by culture or ideology, the individualistic level of identity is considered to be merely one important, but partial, version of what it means to be human. And yet, the combination of the concept of the individual who has choice and volition and the notion of group loyalty as a counter-narrative to enforced assimilation can be seen as progression towards pluralism and respect for difference, at both the individual and collective levels.

A second notion of group identity relates to a more primordial or premodern idea of community and harkens back to closed collective societies, in which individualism plays no ideological role. Today, these societies must function within the modern, globalized world, preserving their subculture by holding on to more collective values; within these communities, expressions of identity may refer to authentic values of the community, tradition or religious scripts. When mediation is used within the framework of collective identity, a natural clash may ensue between the different groups to which the parties belong, and no treatment of individual-level interests will help to repair the rift that a clash like this causes. In fact, attempts to reduce these differences to interests that may be coordinated, or worse, constructively manipulated, can actually lead to intensifications of identity-based conflicts.

${ }^{32}$ Sidney Ratner, Horace M. Kallen and Cultural Pluralism, 4 MOD. JUDAISM 185 200 (1984), available at http://www.jstor.org/stable/1396461.

33 See generally KEN MORRISON, MARX, DURKHEIM, WEBER: FORMATIONS OF MODERN SOCIAL THOUGHT (2006).

34 See generally, e.g., HANS-GEORG GADAMER, ,HERMENEUTICS, RELIGION AND ETHICS (Joel Weinsheinmer trans.) (2011). 
When group identity is at stake, a cultural difference lies at the core of the interaction between the parties. Allowing it to be expressed and to echo through the intervention is important in order to enable the groups to move on to a phase in which they can authentically communicate and perhaps at some point decide to work on shared goals or pursue common interests. Yet, according to models of mediation, especially from the second generation, ${ }^{35}$ these clashes can be considered to be sources of learning and mutual inspiration. As each side hears of the other side's narrative or "mythology of origin and descent," 36 these narratives could, when told well and attentively listened to, lead to mutuality and even intergroup amalgamation. ${ }^{37}$ In some senses, amalgamation is indeed our ideal expression at the level of intergroup identity, in which positive aspects of the different groups are synthesized and new overarching identities are constructed. In contrast to the discourse of rights and interests that characterizes the previous liberal stage of separate individuals, we have here a discourse that is based on dialogue between social identities and engagement with the other.

Expressions of group identity can be found in many second generation interventions in which conflicts between groups or communities are the focus of engagement. For example, in the speech of a participant in the abovereferenced intervention into police-community conflict in Cincinnati, $\mathrm{Ohio}^{38}$ The speaker refers to the goals of investing in collective self-help, community education, and development:

I think Cincinnati is a great city that has a problem of racial tension that needs to be resolved. I also care about progress in the African American population's social and economic position in this city. Both the racial tension and the position of the African American community add fuel to the issue at hand. ${ }^{39}$

For this person, the group to which he belongs is the most important unit of reference. In the face of racial tension, the African American population suffers as a group and needs to be empowered as a group. Thus, in mediating

35 See, e.g., Folger \& BUSH, supra note 27; JOHN PAUL LEDERACH, PREPARING FOR PEACE: CONFlict TRANSFormation ACross CUltures (1995); JAY RothMAN, RESOLVING IDENTITY-BASED CONFLICT: IN NATIONS, ORGANIZATIONS, AND COMMUNITIES (1997).

36 ANTHONY D. SMITH, NATIONAL IDENTITY (1991).

37 JAy RothMAN, From CONFRONTATION TO COOPERATION: RESOlVING ETHNIC AND REGIONAL CONFLICT (1992; reprinted 2012).

38 See The Data, supra note 29.

${ }^{39}$ Id. 
this dispute, it is crucial to address the social and economic conditions. In this context, the goal-setting process that arises from an intense conflict situation is related to the internal development of a group and simultaneously references the difficulties in encounters between groups.

An equivalent expression can be traced when a young participant in the same intervention declares that:

It also bothers me that people see our generation as not knowing how to deal with problems without using violence. Our generation is smart and we can solve problems by talking them over. ${ }^{40}$

In this text, the speaker's generation is his source of group identity and that generation is, he believes, capable of transforming the conflict by resolving problems and building trust.

\section{B. Intergroup Identity}

This last phase in defining and creatively engaging and even redefining identity belongs therefore to our own era and it embraces a form of rooted collectivism-or what Kwame Anthony Appiah calls rooted cosmopolitanism..$^{41}$ It is an intercultural notion of identity, which we refer to as intergroup, and it suits the contemporary ideology of globalization and pluralism.

A person who experiences herself as beyond culture or multi-cultural and as sharing different kinds of social identities-a situation which is perhaps best-described as inter-cultural-has no concrete hegemony to determine which component of identity should prevail; in this situation, identity is perceived as multiple. This is akin to Amin Maalouf's idea of identity that is both vertical (in terms of deep roots in a specific set cultural and historical past) and horizontal (in terms of connectedness to now and other individuals, groups and ideologies one encounters in modern life) ${ }^{42}$

This next developmental stage in thinking about and expressing identity both embraces the group perspective and extends it into an interplay between various group identities that may also be, or come to be, salient for the same

${ }^{40} \mathrm{Id}$. (1997).

${ }^{41}$ Kwame Anthony Appiah, Cosmopolitan Patriots, 23 CRITICAL INQUIRY, 617-39

42 AMIN MAalouf, IN THE NAME OF IDENTTTY: VIOLENCE AND THE NEED TO BELONG (Barbara Bray, trans.) (2001). 
individual (for example, a woman may experience her identity as a woman, as young, and as a police officer at the same time). ${ }^{43}$

This stage indicates a return to the singular private pole of identity, but it is not based on the old liberal notion of individual, atomistic identity. Rather, identity is experienced as an inclusive and enlarged Self. As Walt Whitman famously wrote, "I am large, I contain multitudes." 44

Here, identity is perceived as a negotiation between different selves, which are part of collective loyalties that, rather than clashing, are potentially complementary. Individuals have extensive choice with regard to the form of identity and can flow in and out of various group loyalties, depending on their needs and on the context. ${ }^{45}$ The individual who has grown up in the postmodern globalized world and absorbed the critique of liberalism may possess a multiple identity, informed and influenced by various cultural narratives and texts. Individuals within this context move between different subject-object relations and identifiers according to the context, and their responses are never completely private and do not arise from the black box of the singular mind. Instead, one views oneself as having multiple cultures and collective anchors of identity in each given moment, some which are more or less salient depending on context. Individuality and unique identity is expressed in the manner in which these multiple anchors operate, within the larger context of influences and allegiances; these meld together into something that is simultaneously unique and derivative, individualistic and cultural that cannot be essentialized into a single group category. From the perspective of this stage, the individualistic phase is only one cultural possibility among various different formulae.

In many ways, mediation is a product of this post-modern, universalist view of the good and right. ${ }^{46}$ In fact, many mediators experience themselves as having a multicultural or even post-cultural identity and believe that this ensures their third party flexibility and multipartiality since they can move from one subjective position to another and objectively view a conflict from the balcony. ${ }^{47}$

${ }^{43}$ See Clifford Geertz, The Integrative Revolution: Primordial Sentiments and Civil Politics in the New States, in OLd SOCIETIES AND NEW STATES: THE Quest FOR MODERNITY IN ASIA AND AFRICA, 105-57 (1963) (describing a similar process).

44 WaLt WhITMAN, Song of Myself, in LEAVEs Of GRASS $§ 51$ (1892).

45 WINSLADE \& MONK, supra note 23, at 44-45.

46 See Dale Bagshaw, The Three M's-Mediation, Postmodernism and The New Millenium, 18 MEDIATION QUARTERLY 205 (2001).

47 But see WILlIAM URY, GETTING PAST No 37 (1993) (providing a different use of the balcony metaphor). 
However, while such a view may help to build an inclusive and tolerant world, it may also mask or help avoid the dangerous identity conversation in which one group asserts and seeks to dignify its identity above others. (This in itself can be challenging for the universalist mediator who has been liberated or matured beyond what he may view as such artificial, or primitive constructs). For example, in the well-known work Difficult Conversations the authors recommend that parties "complexify their identity perception in order to overcome identity". 48

We believe that this view is a serious, albeit common, problem in our field, and particularly in cases of interest-based approaches to identity. Just as this approach confounds interests with needs (see below), it also confounds emotions with identities. And since emotions are perceived as irrational so too identity comes to be seen as irrational. Yet as emotions often have a rational grounding, so identity is never irrational and group identities can't be separated out. Thus, the attempt to deal with emotions or overcome identity or separate the person from the problem may be part of the difficulty practitioners face when dealing with deeply rooted conflicts in which emotions and identities are actually at the heart of the problem.

In this paper we argue that when first and some second generation models of conflict resolution try to deal with group identity by deconstructing it and making it more complex through an emphasis on personal emotions, narratives and contact, they mostly fail to fully enter into or deeply empathize with the group level identity. Yet, we believe, empathy with the group level identity is essential in order to move forward towards an inclusive, intergroup level of relations and development. Ideally, at the intergroup level, participants feel a sense of lessened conflict because they are shifting allegiances and loyalties in order to fulfill individual and collective purposes and fill the gaps found in each. For certain groups in a concrete conflict in a given context, a successful complex conflict engagement intervention works better on the level of distinct group interactions. Working on the intergroup level of a deeply-rooted conflict requires some degree of deconstruction and then reconstruction of the identity components of the conflict; that is, certain parties to the conflict may be required to choose a salient identity among their multiple experiences and to stick to this identity in order to contribute to a more significant and constructive process. (For example, in the above noted choice about allegiances as youth, African American, Police officer, in this real instance

48 Douglas Stone, Bruce Patton \& Sheila HeEn, Difficult Conversations: How To DiscusS What MATTERS MOST 118 (1999). 
the person chose to show up as a Police since she decided that group most needed her voice and views). 49

This complex, or fractured, perception of identity twists and shifts according to context and may be individual and plural at once. This selfperception of fracture, which is nevertheless bounded by a cultural lens, emerges for example from a participant in the Cincinnati intervention who refers to the why of the goal of building greater understanding between police and communities in the following way:

When we were younger, all the neighborhood kids played in our backyard. We had friends of all races, we all went to school together. But once we started getting older and going to different schools, we just don't get together anymore. It seems like two worlds. I miss our old one. ${ }^{50}$

Here we find a nuanced approach to the author's identity: he remembers himself as an individual, although still affiliated with a racial group and equal among his peers as a child; however, on the other hand, the boundaries of adult experiences and groups seem more rigid and determine his everyday life. He wishes he could go back to the old distinctive yet inclusive identity. His point is not to make an oppositional group assertion or to go back to an individualistic position that has no reference to the group. Rather he aims to show the elasticity and inclusivity of a pluralistic social identity within the context of one person, group identifiers and intergroup activities.

Another similar expression can be found in the following quote:

I really don't like the way persons are against other persons, including the police. Maybe it goes back to slavery. It's been going on for generations, but we need to start with all the people to change it, like the police chief, the mayor and the council. ${ }^{51}$

Once again, we find acknowledgement of the social aspect of identity, the deep collective difference that determines the boundaries of the self on the one hand, contrasted with the flexibility that exists today and the possibility of transcending the historical divide and transforming it through the will of specific individuals who represent categories (i.e. police) and classes (i.e. leadership elite).

\footnotetext{
49 See The Data, supra note 29.

$50 \mathrm{Id}$.

51 Id.
} 


\section{Identity and Conflict Engagement}

Since its inception, the study of conflict resolution has been antifoundational and has contended that the appearance of the conflict does not necessarily signify its true substance. ${ }^{52}$ This approach calls for avoiding the antagonistic claims that are on the surface and to focus on the underlying layer of the conflict. This hidden layer has been central to any dispute resolution intervention.

Whether this hidden layer is defined as economic interests, emotional subtext, ontological or biological needs, all schools of conflict resolution have repeatedly insisted that working with the underlying level is much more productive and constructive then attending to the appearance of conflict. This section locates, and then re-situates, the role of identity within the search for the ultimate hidden layer in all conflicts and in creative conflict engagement.

Since its publication in 1981, Getting to Yes ${ }^{53}$ ("GTY") has become the standard text for the field (and in particular for the ADR and negotiation components of it). While it began as a text for international negotiators, GTY evolved in to a handbook aimed primarily at domestic conflicts and interests are presented as "the silent movers behind the management." 54 This has been both a boon and burden for the field. It has been a boon because it was with this book that the sub-field of conflict management emerged and gained recognition. It has been a burden because the reach has been larger than the grasp. The publication was followed by the establishment of the Harvard Negotiation Project as the principle go-to place for conflict management training and education. Even though much more nuanced approaches to field, with this approach being merely one important subset, and even though the model has necessarily developed, the field continues to revolve around this original set of terms and methods. In contrast, the alternative the needs-based approach, to which we refer above, has gained "followers" but remains much less known and influential, certainly in domestic conflict engagement work, at least in the United States. ${ }^{55}$

The prescription to separate the people from the problem is one common example. When the problem is indeed about resources, or even about goals that are relatively well defined, this can indeed be a very useful guideline.

\footnotetext{
52 Kevin Avruch, Culture \& Conflict Resolution (1998) 24-27.

53 FISHER \& URY, supra note 19.

54 See FISHER \& URY, supra note 19 at 13.

55 We do note, however, pursuant to our discussion above, that we also view the needs school as limited, due to its individualistic emphasis.
} 
However, when (as we suggest in this paper and elsewhere) ${ }^{56}$ deeper issues such as individual expression and group solidarity are at stake, separating individuals from problems is often not possible because it is the individuals, their group loyalties and their individual and collective identities that are at stake. As we emphasized above, clashing group identities do not need to be managed through separation of their various components; rather, they must be transformed by allowing them to echo and resonate while simultaneously challenging their boundaries. Thus, trying to separate emotions and relationships from "problems" can actually exacerbate the conflict and the forms of its expression.

The fact that the "focus on interests beneath the positions" has become the lingua franca of the field points to a second way in which the GTY model has overreached and therefore narrowed the scope of the field. ${ }^{57}$ Historically and etymologically speaking, the noun interest is a "legal claim or right; concern; benefit, advantage;" or "to concern, make a difference, be of importance," and finally even more narrowly as money paid on a loan. ${ }^{58}$ In terms of its professional usage in industrial relations, interests are focused on acquisition and retention of necessary material resources for business purposes. In international affairs the "national interest" is about control of territory, economic wellbeing and the power to protect and promote such interests. It is useful to note here that when Fisher and Ury began their work, they did not intend it for a domestic audience, but rather to guide international diplomats and business leaders so that their negotiations would be more productive. ${ }^{59}$ Although when defining interests in their writing they refer to fears, needs, and emotions, the more economical, managerial image of interests has prevailed as the legacy of their constructive formula of conflict engagement.

Moreover, because this approach elides differences between interests and needs-by claiming that "The basic problem in a negotiation lies not in

56 See JAY ROTHMAN, FROM CONFRONTATION TO COOPERATION: RESOLVING ETHNIC AND REGIONAL CONFLICT (1992); Rothman supra note 36; Rothman supra note 1 .

57 We present another example of the over-reach-one might even label it imperialism-of the interests framework. Recently, one of the authors attended a lecture by a mediator who had been studying traditional cultures and their styles of mediation. Acknowledging that he was still in the early stages of his investigation, he nevertheless stated that it was clear to him that pursuit of a win-win outcome based on shared interests was shared by both the cultures he was studying and the Western models.
58
See
Interest,
Online
Etymology
Dictionary, http://www.etymonline.com/index.php?term=interest (last visited Jan. 23, 2012 ).

59 Note here the earlier work of ROGER FISHER, INTERNATIONAL MEDIATION: A WORKING GUIDE (1978) (with help of William Ury), which preceded the domestically focused book GTY. 
conflicting positions, but in the conflict between each side's needs, desires, concerns, and fears" 60 and that needs are the deepest form of interests-it obfuscates some useful tools in analyzing and distinguishing between deeper levels of conflicts (and indeed, deeper conflicts themselves) and, more superficial levels or types of conflicts. In Burton's alternative theory of international conflicts, which evolved in the better-defined and bounded theater of conflict resolution, basic human needs, which are different from interests and include the need for recognition of a distinctive identity, should drive the conflict resolution process. The goal must be the resolution of threats and frustrations to these basic human needs rather than simply the management of the presenting or tangible interests. In eliding the difference between needs and interests, GTY has further over-claimed its role as the forum that fits all the fusses ${ }^{61}$ and it has obfuscated the necessary development of a robust contingency model in which different types and levels of conflicts are addressed with different types of analyses and invention models. ${ }^{62}$ Thus, while the Burton school did provide an alternative view and approach to the then developing field, it was more limited in its appeal, especially since it was focused primarily on the international arena and more narrowly defined deeply rooted conflicts or protracted social conflicts. The Burton school was also limited because it held to an individualistic notion of identity, and thus merely switched the perceived economic perception of human beings with a biological perception. ${ }^{63}$ Moreover, as we have just described, this approach was somewhat

60 See FISHER \& URY, supra note 19.

61 See Frank E.A..Sander \& Steven Goldberg, Fitting the forum to the Fuss: A UserFriendly Guide to Selecting an ADR Procedure, 10 NEGOT. J. 49 (Jan. 1994). Again, the danger of any paradigm-setting approaches such as this one is that it becomes its own worst enemy. While many toiling in its shadow including most of the field forming leaders at PON, from Rubin to Susskind to Sander and even Ury, and later a second generation represented by Stone et al., long tried to broaden the focus of the field, they, for the most part, bought in to some of the central concepts and perpetuated them, such as the assertion that needs are merely a deeper form of interests. This blurring of necessary distinctions, has led to a thin theory and a kind of cultural imperialism that has stultified the field. See generally JEFFREY Z. RUBIN \& BERT R. BROWN, THE SOCIAL PSYCHOLOGY of BargainING aNd Negotiation (1975); Hallam Movius \& LAWRENCE SuSSKIND, BuILT to Win: Creating a World Class Negotiating Organization, (2009); Frank E. A. Sander, Nancy H. Rogers \& Sarah Rudolph Cole, Dispute Resolution: Negotiation, MEdiation, AND Other Processes (5th ed. 2007); URY, supra note 46; STONE ET AL., supra note 46,

62 Rothman, supra note 29.

${ }^{63}$ Kevin Avruch \& Peter W. Black, The Culture Question and Intercultural Conflict Resolution, 16 PEACE AND CHANGE 22 (1991). 
delegitimized when in first emerged because its primary practical and rhetorical needs-based appeal was framed as merely a deeper form of interests, which could be handled with a more skillful application of the same managerial techniques advocated by the GTY School.

The first real paradigm-challenging push in the field, at least when speaking about domestic focus, with broad-appeal and practical application, emerged in the late 90's with the publication of the Promise of Mediation. ${ }^{64}$ This approach labeled the GTY School as linked to an individualistic, utilitarian problem-solving paradigm that had stultified the field. Indeed, Jeffry Rubin himself, who had been an early leader of the PON community, called the book path-breaking and polemical ${ }^{65} \mathrm{Here}$, too, we see that this development had both positive and negative effects. On the one hand, the book challenged the utilitarian satisfaction-based approach of GTY and presented, at least in the first edition, a feminist moral approach based on ethics of care as the basis for mediation. ${ }^{66}$ On the other hand, however, by emphasizing empowerment and recognition in a universalistic psychological mode, without reference to social identity or to aspects of culture and collectivist versions of identity, the book remained largely trapped in an individualistic notion of identity and did not adequately articulate the role of identity in conflict transformation.

It is interesting and instructive to note that Promise of Mediation rose quickly to prominence in the domestic field despite its nearly total exclusion of the needs-based school in its review of the field and bibliography. In some ways, in its eager attack on the interest-based school, the transformative approach overlooked what should have been a more compatible intellectual grounding in the needs-based school, since they both stem from an individualistic grounding. Perhaps this occurred in large measure to what at the time was a lack of intersection between the IR and domestic branches of the field.

With this article we are stepping out beyond the interest-based, needsbased, and transformative approaches, as well as moving between IR and domestic arenas, and the statement we make here is more radical than the

\section{${ }^{64}$ BUSH \& FOLGER, supra note 27.}

65 It is important to note, that like many other early leaders of the PON community, Rubin with his social psychological background also pushed against and broadened the framework, as did, in fact, most of those working there. But the wave of language, techniques, and frankly market driven development was stronger than all of them and the narrow interest-based focus and terminology prevails to this day. As noted, and using a basketball metaphor, it remains the pick around which plays in the field, whether theoretical or practical, are commonly made.

${ }^{66}$ Gilligan, supra note 9. 
statements we have made previously. Until now, we, like most others, have viewed identity as a deeper form of need, and thus we fell squarely within the Burtonian and later the transformative, schools. ${ }^{67}$ Reducing identity to a need keeps it within an individual perspective. We now assert that identity is not merely another engine of deep conflict, the result of threats to or frustrations of basic human needs. Rather, identity is an underlying layer that requires its own distinctive analyses and treatments. In fact, we do not think of identity as fitting in to the category of a basic human need at all; rather it is a basic foundation stone upon which all of human development and interaction depends. From a developmental perspective, transferring from one identity level to another-from individualistic to group and from group to intergroup-enables a broader perspective on human interactions within conflicts and may provide a measure for the evaluation of a successful mediation. 68

However, in order not to fall in the same trap that we criticized in the PON school and the polemicists of the transformative school, our argument is that while identity is an underlying layer in all conflicts, it is not equally salient across all conflicts. This understanding is an essential first analytical step in intervention planning. Although all conflicts can be analyzed and sorted out by classifying them according to their identity level, we do not believe all conflicts are identity-based, ${ }^{69}$ nor do we contend that there is one central forum for all the fusses. Rather we suggest and have been developing a contingency model in which different types and levels of conflicts are matched with different analytical tools and intervention methods. ${ }^{70}$

If we are to succeed in defining identity-based conflict on its own terms, we need to begin with cogent definitions that lead to useful theorizing and intervention design. As we have stated in this paper, we view Identity as a self- perception filled by a cultural formula. This formula can refer to personal, internal needs, and preferences; group characteristics and values; or multiple expressions of within and between group loyalties. Identity varies across individuals, groups, or intergroups, but it always conditions the conflict perception. Parties may perceive themselves as separated maximizers, pursuing their self-interests in the most efficient manner and expressing an individualistic identity. They might be located on the group

${ }^{67}$ Including in indirect ways in BUSH \& FOLGER, supra note 27 , and extending to JOHAN GALTUNG, TRANSCEND AND TRANSFORM: AN INTRODUCTION TO CONFLICT WORK (2004); LEDERACH, supra note 34; KUMAR RUPESINGHE, CONFLICT TRANSFORMATION (1995), and others.

68 Jeffrey R. Seul, supra note 11.

69 As LEDERACH, supra note 34, suggests.

${ }^{70}$ See ROTHMAN, supra note 36. 
level and experience themselves as part of a collective social unit that has a common narrative, or one that challenges the hegemonic identity narrative. They can experience themselves as sharing many social identities and groups and may be considered to be located on the intergroup level. All these experiences are based on the cultural formula that informs identity.

According to this definition and the three types of identity, and following the genealogy of the field that we have described, it should be clear why identity cannot be considered to be an "interest" or even one need among others, and should rather be recognized as epistemologically diverse and as informing other modes of hidden layers. Identity is an ideological framework from which a participant experiences herself and it can be manifested in individualistic, group, and intergroup terms. We believe, or at least at this point in our theorizing find it a useful start, to correlate identity with the three types of expression we label individual, group, and intergroup. The type of identity a person experiences within a certain exchange in a given conflict can vary along the three categories described here, and each one of them informs a concrete frame of conflict perception.

In their classic work, Henry A. Murray and Clyde Kluckhohn ${ }^{71}$ describe how all of us are like no others (individualistic level), some others (group identity level), and all others (intergroup level). They write:

All of us are like everyone else. We share common needs, wants, values, desires, goals. All of us are like some other people-we all belong to groups, tribes, families, organizations, with shared values and personalities. And every one of us is like no one else - every one of us is unique - a concrete accumulation of forms of identity, based on social frameworks. ${ }^{72}$

We claim that mapping self-expressions within a conflict according to this three-level scheme of analysis is a necessary first step to choosing an intervention method. The next section will deal with this procedure.

\section{When Third Party Interveners Work with Identity}

Based on the three levels of identity-individual, group, and intergroup - and the central role of identity for understanding conflicts and their context, we suggest a diagnostic procedure for each conflict; this procedure will enable the intervener to effectively an constructively choose

71 Kluckhohn Et Al., Personality IN NAture, Society, ANd Culture ( $2 \mathrm{~d}$ ed. 1953).

72 Id. 
the proper form of intervention according to the experienced identity level of the parties.

According to the current stage of research, we claim that identity levels can be best diagnosed by using narratives (that is, oral or written texts) provided by the participants in a conflict intervention. A self-expression, elicited in the form of a narrative framed according to a constructive interviewing question such as "Why do you care deeply about achieving a specific goal you have mentioned?" may give good indication as to the dominant level of identity in a specific conflict context. As can be seen in the illustrative texts provided above, when parties refer to personal needs, individual emotions and economical motives, they will be characterized as operating on the individual level. When they discuss group values and refer to ideological motives they will be characterized as having a group identity, and when they oscillate among group and universal (e.g. "humanity") identifiers, they will be defined as having an intergroup perspective. We plan to develop a coding guideline to provide this diagnosis and we recommend that once the dominant identity level of both parties has been recognized, a method of intervention should accordingly be matched to the conflict.

A basic assumption that emerges from our analysis is that reference to the intergroup level provides the most comprehensive and accurate theoretical framework to describe identity in any conflict. This is based on our assumption that that identity is primarily socially constructed and through several social frames. The intergroup framework can thus provide a theoretical analysis for any conflict, but we assert that sensitivity to the nuanced play of identity levels within each conflict does not mean that we aspire for each of the parties to developmentally shift into intergroup identity. Rather it becomes a mirror or framework for analysis, comparison, and intervention choices.

Although the intergroup framework may provide a comparative explanation for any conflict, in actual disputes individuals experience themselves as separate or struggling over resources (individual level), or as part of a collective and belonging to one concrete community (group level). Indeed, based on our experiences in interventions in various conflicts, we are suggesting that aspiring to the intergroup level can sometimes be unproductive. Instead, we argue, focusing on the group provides a lens by which we can best understand the ways in which individuals understand and express their sense of solidarity and defensiveness since, by definition, groups are the building blocks on which amalgamated intergroup identities are forged. 
Our diagnostic procedure suggests that after participants have articulated their dominant identity and this has been coded, conflict engagement professionals should proceed in the following way.

In cases of parties who share the individual level experience of identity in relation to the conflict, conflict management professionals will often find that problem solving mediation and similar types of interests/needs based models of intervention are useful. These models allocate resources and deal with emotions as personal expressions, but generally do not generally emphasize any cultural, group oriented or ideological notion of the conflict.

In cases of parties who share the group level experience of identity and perceive these group identities as clashing, second generation models of conflict engagement (which extend beyond the needs and interest-based formulas of the first generation) may be more useful in order to first affirm and then complexify the group identity-to question it, deconstruct it, and make it available in a transitional moment for more nuanced and interactive mode with other groups and their identities. This mode of intervention assumes a more humanistic and moral approach to mediation and is compatible with Buberian notions of I-Thou dialogue ${ }^{73}$ and with the Levinasic philosophy of infinite love while encountering the face of the other. ${ }^{74}$

Parties at this stage should not be pushed into the intergroup level of identity. Second generation models of conflict resolution are capable of transforming identity conflicts into an intermediate level between group and intergroup, but they should not aspire to a full expression of this third level. Instead, dialogues at this level, need to unfold through some form of collective action in pursuit of minor deconstruction of the existing social identities. In interesting ways, this third level of intergroup identity is akin to the notion of the mediator as multi-partial who can both appreciate and in important ways even empathize with all the perspectives of each group and its identity.

In cases of parties who share the intergroup level of identity, conflict can often be mutually deconstructed and reconstructed by acknowledging the multi-dimensional social constructionist perspective of the situation. However, when conflict exists between groups and a third party intervention is needed, the possibility of a certain degree of negotiation of identity may still be possible, assuming that individual and group identities are first acknowledged, articulated and recognized. It may even be possible for

\footnotetext{
73 See generally MARTIN BubER \& RoNALD GREGOR SMITH, I AND THOU (2d ed.

74 See generally EMMANUEL LEVINAS, TOTALITY AND INFINITY (1969).
} 1958) 
opposing identity groups to find bridges between them when they are readied for and seeking concrete solutions to the concrete problems they face internally or interactively.

In cases of parties who do not share the same identity perception, our working hypothesis is that pushing towards the group identity and working on the intra-group dimensions of conflict and cooperation may be the most productive intervention to condition the participants for creative intergroup conflict engagement. Following that, when one party perceives the conflict as based in the individual level and the second perceives the group level to be more salient, working on the group level may open the eyes of the first party to get to a deeper level of understanding of the conflict. The same is true for parties who differ at the group and intergroup levels, and even between the individual level and the intergroup level. Work on the group identity level may be the default intervention tool to deal with complex interactions between identity levels. Parties will many times be asked to choose a salient identity component among various experiences they have in order to enable a significant intervention process.

\section{CONCLUSION}

First, we believe that it is both theoretically interesting and practically useful to view identity as an underlying layer of all conflicts that can be more or less salient. The level of salience-low in personal conflicts and high in group conflicts-will determine the type of intervention a third party may conduct. This schema is thus a vehicle for both conflict analysis and intervention planning.

Second, conflict engagement models should fit the level of identity on which they operate, and working at the group level should be a default choice when various levels of identity interact. Individualistic identity-_'I am like no other"-informs an underlying layer which consists of needs and interests. The mainstream models of conflict resolution, such as the pragmatic GTY formula of Fisher and Ury ${ }^{75}$ are based on an individualistic epistemology of identity, and therefore negotiating interests and even identity is paramount in their operation.

In the Group Identity-in which "I am like some others"--the primary experience of the individual is that he or she is part of a specific group (and of course one can be part of many different groups, even contending ones), and he or she views identities as largely socially constructed and collectively expressed. Emotions and sensibilities are related to the group's culture and

75 FISHER \& URY, supra note 19. 
can often be understood and explained by using ideological frameworks. Models of conflict resolution that deal with these types of conflicts, within and between groups, suggest engagement and dialogue and assume that interests and needs are only the upper layers of conflict. Underneath are the ideological frameworks and the social perceptions that inform them. The private is public and is colored in structural terms. Currently existing models that deal with identity, such as ARIA and Transformative Mediation, usually focus more on the social-psychological experience of collective identity and less on the content that informs these experiences. Achieving goals, satisfying needs or promoting efficiency is not a salient element within these models, not because they necessarily hold a different moral philosophy, ${ }^{76}$ or because they are not focused on resolving conflicts, but because the complexified group identity is measured in different terms

The Intergroup Identity, in which one feels "I am like all others," incorporates the previous notions since it contains the assumption that individuals are socially constructed as in the group identity level, but it weaves this assumption into a notion of identities at play with each other, much as individuals interact and co-create each other in their interactions. According to this level, a participant in conflict may experience herself as a complex being, having multiple and socially constructed frameworks that inspire diverse self-perceptions and encounters. In this phase, shifting from one identity to another within the conflict intervention process is common. A party can start by discussing financial interests (an individualistic interest that often requires collective action), move on to emotional and ideological needs (in particular, in the face of existential threat or frustrations), and conclude with moral and spiritual values (of greater purpose and being part of a larger whole). The underlying level of conflict is not fixed according to this perception and oscillating between diverse "subject positions" may be an integral part of the intervention work.

Third, work on the group level of identity should be conducted through a shift to an intermediate level between group and intergroup. Although the intergroup level is conceptually the more accurate and can be used for analysis and theorizing about identity in conflicts, in terms of conflict engagement work, this is not the most productive. We have found that the most productive method to deal with what were referred to as identity-based conflict (conflict based on encounters between group identities) entails aspiring to an intermediate level in which group identity is challenged, but in which intergroup identity is not a goal in and of itself. Challenging the group identity, deconstructing it, letting it echo and resonate in the other's speech,

${ }^{76}$ BUSH \& FOLGER, supra note 27. 
and exploring emotional its vectors through a humanistic dialogue may be the better mode in order to constructively transform a conflict, rather than an overall deconstruction into multiple encounters between various indeterminate group identities.

Fourth, this paper lays out the foundation for future extensive conflict engagement research which will articulate in a nuanced manner the way in which various model of conflict engagement deal with group identities and reconstruct them. ${ }^{77}$ For example, one of our current projects involves developing a coding system that will enable theorists and practitioners to map identity expressions and to examine conflict interventions based on our diagnostic hypothesis. Our next stage in the development of this project will involve rich case studies of concrete interventions in identity conflict and will examine and code identity expressions by using the conceptual framework we have presented.

${ }^{77}$ We also would like to note that, since this paper is being given at a conference, the authors have already developed a preliminary plan for possible research which this paper may help focus, which entails examining legal formal intervention in identity conflicts as expressed, for example, in Supreme Court decisions. Are court decisions by definition focused on the individual level of identity? Is there a possibility to transform identity conflicts through court decisions that emphasize the group level? 
